\title{
Competition and accessibility in school markets: empirical analysis using boundary discontinuities*
}

\author{
Stephen Gibbons ${ }^{1}$ and Olmo Silva ${ }^{2}$
}

February 2006

\begin{abstract}
Advocates of market-based reforms in the public sector argue that competition between providers drives up performance. But in the context of schooling, the concern is that any improvements in efficiency may come at the cost of increased stratification of schools along lines of pupil ability and attainments. In this chapter, we discuss our empirical work on competition and parental choice in English primary schools and present a methodology for identifying competition effects that exploits discontinuities in market access close to education district boundaries.
\end{abstract}

Keywords: Competition; Schools; Segregation, Attainments, Discontinuities. JEL Classifications: I20, H70, R5.

\footnotetext{
* Preliminary; comments are welcome. We would like to thank the Department for Education and Skills for funding this work under the Centre for the Economic of Education work programme, participants at various seminars and Joan Wilson for stimulating discussions on this project. We are responsible for any remaining errors.

${ }^{1}$ Department of Geography and Environment, Centre for the Economics of Education and Centre for Economic Performance, London School of Economics.

2 Centre for the Economics of Education, Centre for Economic Performance, London School of Economics; and Department of Economics, European University Institute, Florence.
} 


\section{Introduction}

Government education policies in England, as in the US, have increasingly favoured competition among schools. Supporters of market-based reforms argue that autonomy and competition among education providers are effective tools with which to lift student achievements. These gains are assumed to come from market discipline incentives and better matching of pupil needs to school provision. Yet, critics of these ideas point to increased demographic stratification of schools as the most likely outcome, with high-ability children of highly-motivated, high-income, parents securing admission to the best schools.

Despite a growing literature on the topic, evidence on the effects of quasi-markets in education remains rather mixed. One reason for this is that it is difficult to find truly exogenous variation in the competitiveness of school markets with which to identify the effects of competition on pupil attainments and stratification. In this chapter, we discuss evidence from primary-phase schooling in England, which, we argue, succeeds in isolating very localised variation in school accessibility close to attendance district boundaries. The chapter highlights the potential for the use of data with detailed geographical information in the identification of market effects, and in empirical analysis more generally.

The starting point for the empirical methods and results we present is a large and detailed pupil census that includes precise information on pupil and school addresses. This allows us to: (i) use the de-facto pupil travel-to-school patterns to construct choice indices from the number of alternative schools available to a pupil at their place of residence; (ii) construct measures of competition faced by a school based on the number of choices available to the pupils it enrols. We argue that these are meaningful measures 
of choice and competition, which offer a conceptually attractive alternative to more traditional indices. Indeed, the same idea could be extended to analyse competition in any markets, when data is available on the location of service providers (such as health care facilities, retail outlets, entertainment centres) and the location of potential consumers. The drawback of our suggested indices is that they are potentially endogenous to the quality of service provided - particularly in the case of schooling, where it is well known that families engage in Tiebout-type residential sorting to secure access to schools of their choice. We suggest that this problem can be overcome when market areas have clearly defined boundaries - as is often the case in public sector services - because these introduce discontinuities in market access from which the effects of choice and competition can be identified.

The short summary of our empirical work on English schools is that competition measured as the number of alternative school choices that pupils attending a school have - has no effect on the performance of schools; although there are significant correlations between school competition and mean pupil attainments, these relationships are not causal. On the other hand, school competition seems to exacerbate polarization of schools by student attainment; while not statistically significant, our estimates hint at fairly large impact of school-market competitiveness on stratification. As such, our results cast additional doubt on there being any real performance benefits from policy to promote competition in schooling markets; they also suggest there could some cost in terms of increased stratification to be expected from quasi-market reforms.

The remainder of this chapter is organised as follows. In the next section, Section 2, we discuss some of the key empirical literature on competition in school markets. In Section 3 we outline our methodology, discuss the merits of our indices in comparison 
with alternatives, and show how our approach to identification relates to some other works exploiting geographical discontinuities. Section 4 explains why our methods are appropriate in the context of English primary schools, summarises our previous work on competition and pupil achievement, and presents new results on the effects of competition on school stratification. Concluding remarks follow, in Section 5.

\section{Theoretical issues and general empirical approach}

\subsection{Background and literature}

While broadly heterogeneous in their details, public school admissions systems can be broadly organized around two 'ideal' models of school provision: a) neighbourhood based systems; and b) choice based systems. In neighbourhood based models, admission is determined purely by where a pupil lives, typically with rigidly defined catchment zones. Choice-based systems, instead, are intended to give parents a wider choice set that is not limited to neighbouring schools.

Traditionally, public schooling systems have been neighbourhood-based, but this tends to tie school quality to the socioeconomic status of local areas and has become in many public and policy makers' imaginations at least - linked to poor standards. Since attempts to find appropriate ways to raise standards using resource-based interventions have met with mixed success (Hanushek (2003)), attention has turned to interventions that change the incentives for school leaders and teachers; among these, market-oriented reforms of public education have found growing support. At the most basic level, this involves changing the school admissions system to increase parental choice and adjusting the system of funding to reward schools that attract pupils and 
penalise those that do not. This creates direct market incentive mechanisms, with popular schools gaining pupils and additional funding, and unpopular schools failing to do so, and eventually closing. Additional benefits may come in the form of allocative efficiency gains, if pupils can find schools that are better matched to their educational needs and preferences.

Despite policy enthusiasm for these reforms, evidence of their performancerelated benefits remains very mixed. Much of this comes from a wide range of studies analyzing the US experience. Some of these explore the effects of implicit variation in the level of choice available in different school markets on pupil achievements (e.g. some of the work reviewed in Belfield and Levin (2003), Hoxby (2000) and Rothstein (2004)). A second approach evaluates the effects of the competition threat imposed on state schools by private institutions (see Hoxby (1994) and (2004)). Finally, another body of research evaluates the impact of policy changes introducing greater competition into geographically localised educational markets (Cullen et al (2003), Hoxby and Rockoff (2004) and Hoxby (2003)). These studies are mixed in their findings, and Belfield and Levin (2003) suggest 'the gains from competition are modest in scope with respect to realistic changes in levels of competition' and that many results are statistically insignificant.

Evidence for Britain is more limited, but similarly mixed. On the one hand, Levacic (2004) finds that secondary school head-teachers' of self-reports of perceived competition are linked to school performance indicators. Similarly, Bradley et al. (2000) show a number of 'market' type effects in secondary education following admissions reforms in the late $1980 \mathrm{~s}$ - for example, schools that performed better than their neighbours attracted more pupils. On the other hand, Clark (2004) reports that reforms 
that handed more power to schools (in late 1980s) only exerted modest efficiency gains through competition effects. Finally, Gibbons et al. (2006) - with results related to those we report later - find little evidence of a positive impact of competition and choice on primary school pupil achievements.

Critics of choice-based reforms point to their potential costs in terms of increased stratification of schools along socioeconomic lines, although the theoretical foundation for this claim is not entirely sound. The idea is that higher socio-economic status parents benefit more from choice-based interventions, as they are better equipped at making good decisions about school quality and getting what they want from the admissions authorities, as well as less constrained by transport costs. However, school choice under a neighbourhood-based school admissions system can be exercised by residential choice, which can just as easily lead to stratification through the housing market. There is, for example, ample evidence that school quality influences local housing prices in neighbourhood-based systems (Black (1999), Gibbons and Machin (2003) and (2006), and Kaine, Staiger and Reig (2005)), which indirectly suggests stratification by income.

Evidence that looks more directly at the stratification effects of choice availability is more limited, but again mixed in its conclusions. For the US, Hoxby (2000) suggests that the effects of choice on productivity are more likely caused by competitive pressure, rather than sorting. To stronger conclusions comes Hoxby (2004): enhanced school choice (mainly voucher systems and charter schools) is not associated with more cream-skimming and segregation. Yet, findings in Rothstein (2004) and Smith and Meier (1995) provide ground for opposite conclusions: parents value peers more than effective schools; most choice based policies produce their effects via sorting. 
UK based evidence has also been produced on this issue. On the one hand, Bradley et al. (2000), Bradley and Taylor (2002), Goldstein and Noden (2003), and Burgess et al. (2004), among the others, suggest that increased competition and greater parental choice are associated with more polarization in English secondary schools. On the other hand, Gorard, Taylor and Fitz (2003), summarizing the results of a large-scale research program assessing the impact of competition on segregation in English secondary schools, show that these became less socially segregated in the 1990s after the introduction of the market-oriented reforms during the late 1980s. Yet, to the best of our knowledge, no in-depth analysis of the impact of school competition on the polarization (and performance) of primary institutions exists; moreover, our methods are unique in finding credibly exogenous variation in school accessibility, with which to identify the effects of competition on pupil stratification and achievements.

\subsection{Defining and measuring competition}

Our modelling strategy is motivated by the following conceptual points: choice availability is a property of residential location and depends on the accessibility of alternative service providers; competition is a property of the location of service providers and depends on the number of alternatives available to users of the service.

A starting point for the development of indices that measure choice and competition in public-sector schooling is the assumption that residential locations differ in terms of the accessibility of alternative schools (or service providers in the general market context). This means that choice amongst schools is more constrained in some places than others, in part because of the transport costs involved, but also because of institutional barriers to access that may apply even if a school is geographically within 
easy reach. The level of competition that a school faces in the market is in turn dependent on the number of alternative choices that were available to its pupils.

The existing literature that measures the effects of competition in public sector markets has largely inherited techniques from work in industrial organisation and takes one of two approaches. Firstly, competitiveness of a market may be defined in terms of an index of market concentration, such the Herfindahl index, using the share of pupils in different schools (or the share of pupils in different admissions districts) in some predefined school market area. The market area can be an education authority's zone of jurisdiction (Bradley et al. (2000)), an entire metropolitan area (Hoxby (2000)), or some other geographical area. A drawback of this approach is that low market concentration cannot really be equated with more choice and greater competition unless all operators in the market are equally accessible to all customers. Geographical restrictions on school admission mean that this criterion is unlikely to be met, unless the notion of choice under consideration includes Tiebout choice that is exercised by residential relocation (as in Hoxby (2000)). This seems however a contradictory way to define competition when the idea of relaxing constraints on choice is usually to offer more alternatives conditional on where a person lives.

A second approach is based on the reasoning implicit in spatial competition theories (Hotelling (1929)), where what really matters is the number of providers that can be reached within a given travel cost, time or distance. The simplest way to operationalise this is to define a provider's market area as the area encompassed by a circle of fixed radius, then to consider all people living within this area as potential consumers and all other providers within the circle as competitors. A first drawback of this approach is that the number of providers (and consumers) within a fixed radius is 
dependent on their areal density, so it becomes difficult to disentangle competition from general urban density effects. Another drawback is that a fixed distance represents very different travel times in urban, suburban and rural environments, so it is hard to see that a fixed radius circular region is meaningful as a market definition in all of these cases. Furthermore, geographical barriers that may obstruct access (rivers, railways, ravines etc.) are easily ignored. More sophisticated analyses try to model market areas on likely journey times. These methods take account of urban-suburban-rural differences and geographical barriers by measuring distances along transport networks, and by adjusting the distance limits of the market area to take account of travel speeds along different classes of road and different types of built environment. A major limitation of this approach is that it requires geographical data on transport networks and is very dependent on the assumptions made about travel mode and travel speeds. For example, a market area defined for schools in terms of car drive times (Burgess et al. (2004)) may not be appropriate if school-travel is usually on foot or by bus.

The indices of competition and choice we develop here are grounded in this second approach, but circumvent some of its problems by inferring a school's catchment area from the actual travel patterns of its pupils. This allows us to construct an index of choice availability at a residential location based on the number of schools that could easily be reached from that location - ease of access being inferred from the actual travel behaviour of neighbouring pupils. As a first step in developing these indices, we find the spatial coordinate pairs of each school $j$ and each pupil $i$ 's home address, and use a geographical information system $^{3}$ to compute the straight line distances $d_{i j}^{j}$ between a pupil's home address and the school he or she attends. We then

\footnotetext{
${ }^{3}$ We use the industry-standard ESRI ArcGIS software.
} 
take the median of distances $d_{i j}^{j}$ for each school and define this distance $\bar{d}_{j}$ as the radius of the catchment area for school $j .{ }^{4}$ Finally, we compute the distances $d_{i k}$ between a pupil's home and the other schools in the local area (within some limiting distance, e.g. $10 \mathrm{~km})$. A school $k$ is then classified as within the feasible set of choices for pupil $i$ if the distance between pupil $i$ and school $k$ is less than the radius of the market area for school $k$, that is if $d_{i k} \leq \bar{d}_{k}$. The choice index for pupil $i$ is defined as the number of schools that fall in this set of feasible choices. The choice index thus depends on place of residence and the travel patterns of pupils in neighbouring schools.

The next step is to infer a measure of the competitive pressures faced by each school in our study area, from this choice index. For a given school, the competition it faces depends on the number of feasible alternatives its pupils had available; hence a natural competition index is the average number of choices available to pupils in that school. This is easily derived as the mean of the choices indices of the pupils on the school role. The derivation of the competition index is illustrated in Figure 1, where the triangles represent schools, squares represent pupils, and the circles represent their market areas.

\section{FIGURE 1 ABOUT HERE}

\footnotetext{
${ }^{4}$ For the results that follow, we also experimented using the $25^{\text {th }}$ and $75^{\text {th }}$ percentiles of the pupil homeschool distance distribution, rather than the median. Our conclusions are robust to these experiments.
} 


\subsection{Measuring performance and stratification}

As outlined above, the debate about the effects of expansion of competition and choice in public services centres on the influence this has on performance and stratification across institutions. The type of competition we have in mind in this chapter is one of spatial competition: state schools compete with others for pupils in a community in order to maximise their revenues and minimise the costs associated with disruptive and challenging pupils. Since state schools cannot easily change location or vary their price, they can only increase their market share by offering a higher quality product. This is one reason why we might expect schools in more competitive environments to offer their pupils higher educational standards. ${ }^{5}$

In the context of schools, better performance is usually taken to imply higher pupil attainments. Therefore it has become standard to measure pupil attainments in terms of test scores and to assess the effectiveness of a school in terms of the gain in attainments of pupils enrolled there over a number of years. In the empirical wok described below, we follow this approach and consider the gain in pupil attainments between age 7 and age 11 as the main 'output' of primary-phase schooling (i.e. what is called pupil 'value-added').

Stratification, on the other hand, is a more complex issue, since it is not obvious along what demographic or educational lines this should be measured, or how it should be measured. Indeed, whether stratification is considered a problem depends on the interaction between stratification and performance - if, for example, peer group quality influences pupil attainments - or on social preferences over the degree of integration of

\footnotetext{
${ }^{5}$ Although there are arguments that would lead in the opposite direction, such as competition leading to more stressful teaching environments or higher pupil turnover; see for example Hanushek et al. (2004).
} 
pupils of different abilities and social backgrounds. In our view, the key concern regarding school stratification is the mix of pupils in terms of their abilities and attainments; therefore, we focus our empirical work on this.

Competition could be causally linked to stratification in abilities and attainments in two ways. Firstly, if schools can choose which pupils they admit, then competition may increase the incentives for schools to try to select pupils who are easier to teach and are likely to boost their performance indicators; some schools may win out over others in this game. ${ }^{6}$ More importantly, the degree of competition in a school market is, by our definition, related to the number of choices that pupils and their parents have available to them. Increased stratification will therefore be a by-product of increased competition if expansion of choice leads to greater sorting of pupils across schools along lines of ability or other demographic characteristics that are correlated with ability.

Measurement of stratification also poses some conceptual and empirical problems. It is possible to approach this in two ways, either in terms of the between-group inequality in school means, or within-school inequality in pupil characteristic. Stronger sorting of pupils into schools by some characteristic will be evident in a decrease in the within-school dispersion and an increase in between-school dispersion. A common way to look for stratification in some characteristic $x$ is to look at a measure of the dispersion $x$ between schools in a market area, using segregation indices such as the dissimilarity index, or inequality measures such as the Gini coefficient, or standard statistical moments. $^{7}$

\footnotetext{
${ }^{6}$ In the English primary school system, this is unlikely to be a major issue since only a small proportion of schools run their own admissions.

${ }^{7}$ For an interesting discussion about the properties of segregation and stratification measures see Massey and Denton (1988).
} 
We adopt a different approach that takes advantage of pupil level micro data, and explicitly model the inequality in $x$ across pupils within a school. We define stratified schools as those characterized by a more homogenous pupil enrolment (e.g., either predominantly good or predominantly bad pupils), whilst less-stratified schools are more mixed in terms of student attainment. An advantage of this approach is that it allows us to model the effects of competition on stratification at school level, rather than at the level of some predefined market. However, we can also compare the effects of competition on within-school pupil inequality with the inequality in attainments within the school's catchment area (as defined in section 2.2).

We will focus on stratification in attainments of two cohorts at two times in the school career: early on in primary schooling at age 7 - the earliest point at which we can measure pupil attainments; and at age 11 when pupils leave the primary school system and move on to secondary school. The first measure is an indication of stratification in terms of the schools' pupil intake; the second measure is an indication of the stratification that exists as a result of these intake differences, plus any influences over the intervening years up to the time pupils leave primary school. In both cases we adopt the Gini coefficient as an index of inequality. We use the Gini coefficient as a measure of dissimilarity between pupils in a school (not between schools); this approaches zero when all pupils at a school are similar in terms of their attainments and tends towards one when pupils are more heterogeneous. To state it differently, a school in a highly stratified system will have a small Gini coefficient, while school in a less stratified system will have a high value for the measure ${ }^{8}$

\footnotetext{
${ }^{8}$ We have experimented with alternative measures of polarization, such as: the $90^{\text {th }}-10^{\text {th }}$ percentile ratio; the $75^{\text {th }}-25^{\text {th }}$ percentile ratio; and the coefficient of variation. Our main conclusions were fully confirmed.
} 


\subsection{Competition and choice near administrative boundaries}

We argue that the choice and competition indices defined in Section 2.3 offer an improvement over existing methods, in that they are based on observed pupil travel patterns. This means we can be more confident about inferring which schools are accessible from any residential location; but this in turn brings some disadvantages because pupil travel patterns are the joint outcome of residential location and school attendance decisions, meaning that the indices are potentially endogenous in models of school quality and stratification.

As a first example of this kind of problem, note that it is well known from the literature on the effect of school quality on housing prices that schools have an influence on local housing demand (op. cit.). This has a bearing on our choice and competition measures, because any tendency for residential crowding of similar families around good schools would tend to shrink the travel area of these schools, making them seem less competitive and more segregated. Conversely, if motivated families with highachieving children are more successful at exercising choice (conditional on residence), then more popular, higher performing and potentially more segregated schools may appear competitive, even though it is parental choice that has spread their geographical intake and increased their polarization. Moreover, the diversity of pupil attainments within a school must also be tied to diversity in pupil attainments in the neighbouring area, which in turn could be related to fragmentation in terms of housing and environmental characteristics and so to school accessibility. Finally, although school opening and closures are quite rare, it is not implausible that the current spatial distribution of schools is related to the socioeconomic characteristics of an area, and consequently, via housing markets and family background, to its pupil characteristics 
and polarization. In particular, we suspect that faith schools may operate in places where economic and educational conditions are more favourable.

So, identification of the causal effects of choice and competition on pupil attainments and stratification poses a serious challenge. To succeed, we require variation in accessibility that may determine school quality and the within-school distribution of pupil attainments (through competition and choice), but is not itself determined by pupil or parental preferences or otherwise related to neighbourhood characteristics. As a starting point, we argue that such variation exists because different residential locations that provide access to a particular school can be very different in terms of the number of alternative schools that are available. Importantly, and plausibly, we assume that is the quality of a particular school that is the object of choice and not the range of alternatives available. Nevertheless, we need some specific sources of variation that we can use as instruments for school choice and competition in our school quality and stratification regression models.

One possibility that arises out of earlier literature is to exploit discontinuities in accessibility that occur around geographical barriers such as rivers, roads and railways, which obstruct access to schools in one or more directions; similar ideas have been used in the past in the analysis of school competition (Hoxby (2000)), neighbourhood stratification (Cutler and Glaeser (1997)), and other areas. But these tangible geographical features are unsuitable when we are worried about the interaction between residential choice and school quality, because these features tend to divide up neighbourhoods along socioeconomic strata and are linked to environmental amenities that are in themselves factors in household location decisions. For instance, finding that attainments are lower for pupils living in homes with poor school accessibility close to 
railway lines could easily be explained by the fact that these pupils come from poorer families living in low-cost housing, rather than any causal impact from reduced choice.

Instead, we propose to identify competition effects by variation in accessibility that occurs close to the boundaries of the administrative authorities that are responsible for school admissions - namely Local Education Authorities (LEAs) in the English school system. Pupils living close to these boundaries, relative to other pupils in the same education authority, face a restricted choice set because institutional barriers make it harder to access schools on the opposite side of the boundary; this implies they are more likely to attend their closest school, than are pupils living in more central locations, because the average cost to the alternatives is higher. ${ }^{9}$

To see this, consider Figure 2: this shows a linear district with 5 schools $k, m, n, p$, $q$ spaced at equal intervals. Schools $k$ and $q$ are located at the district boundaries at the left and right ends of the district respectively. The dashed lines show the cost of reaching each school, from each point $i$ along the linear district. The bold line shows the average cost of reaching schools other than the nearest school, at any point $i$ along the linear district. As can be seen, the average costs of travel to schools other than the nearest is higher for residents near the edge, than in the centre. As a result, residents near boundaries will be more likely to attend their local school, and schools nearby LEA boundaries will mainly enrol pupils from of local families, who have that school as the nearest choice.

In conclusions, schools in locations close to LEA boundaries face less competition because: a) the catchment area shrinks in radius and land area, closer to catchment area boundaries; b) the catchment area may be partially truncated on one side, which is a

\footnotetext{
9 The underlying assumption is that the probability of family $i$ attending school $j$ is decreasing in the distance to the school $d_{i j}$, due to transport costs.
} 
restriction we can impose by excluding the few pupils who do cross LEA boundaries in the calculation of our competition index. This means that we can use distance of a school from a boundary as a predictor of the competition it faces in the local school market. As it turns out, a) is most important in terms of driving variation in our competition index.

FIGURE 2 ABOUT HERE

In general, the distance of a place from an administrative boundary will provide a valid instrument for choice availability and the level of market competition at that place if: a) the administrative boundary increases the costs associated with access to services on the opposite side of the boundary; b) distance from the boundary is otherwise uncorrelated with the outcomes that are being analysed. The extent to which such barriers exist and are impervious depends on the particular institutional context, but we argue below (and demonstrate in our estimates) that LEA boundaries act as real impediments to access in the English primary school system. Moreover, there are no strong reasons for believing that households have any preference about how close they live to boundaries relative to other households in the LEA, or that household 
characteristics are correlated with this distance, or that teaching quality and other factors that drive school effectiveness are directly linked to it. ${ }^{10}$

A similar strategy might be appropriate in the analysis of competition effects in public health and other services, when access is allocated according to zone of residence and discontinuities in accessibility occur close to administrative boundaries. For example, access to general practitioners or hospital medical services provided by a local health authority may be limited to those living within the health authority's jurisdiction. In these cases, distance to health authority boundaries may provide appropriate instruments for the level of competition measured amongst neighbouring hospitals, when there is unobserved area heterogeneity which may be correlated with competition and performance measures (a problem that is often only partially addressed, e.g. Propper et al. (2004), Mobley (2003)).

Closely related thinking lies behind studies which investigate the effects of market access when there are changes in national borders or their permeability. Examples include changes that occurred during German division and re-unification (Redding and Sturm (2005)) or close to the Mexican border as a result of the North American Free Trade Agreement (Hanson (2003)). Our strategy has similarities with these approaches, in that competition, like market access, declines as one moves closer to the boundary on either side. However, because we have observations on both sides of multiple boundaries, we are able to distinguish competition effects from more general monotonic changes that may occur in one direction over the study area. Our approach is, however, distinctly different to the type of empirical analysis that exploits the discontinuities in the level of some variable of interest that occurs as one moves from one side of a

\footnotetext{
${ }^{10}$ In fact, evidence discussed in Gibbons et al. (2006) suggests these assumptions are empirically valid.
} 
boundary to the other - for example the boundary fixed effects strategy used by Black (1999) and Kane, Staiger and Reig (2005) in the analysis of school quality effects on house prices, and Bayer and McMillan (2005) in the context of school choice.

\section{Measuring the effects of competition in primary schools in the London} metropolitan area

\subsection{Data and context}

If our proposed methods are to work, we need a setting where there is some freedom of school choice, given where a family lives, but where there are constraints that mean that some places offer greater accessibility to schools than others. We argue here that the primary school system in and around London provides such a context.

The current state-school system in England is a hybrid of a neighbourhood-based and a choice-based system. Since the Education Reform act of 1988, the principle of choice has been extended to a greater or lesser extent in different districts, (see e.g. Glennester (1991)); the trend continues in more recent legislation (e.g. school Standards and Framework Act 1998 and the Education Reform Act 2002). Although competition in secondary (post-11) education tends to dominate the political landscape, we consider the effects of competition at the primary (pre-11) phase. The reasons for this are partly methodological: travel distances have a greater role to play in primary school choice (than for secondary schools), because children of this age are not independent travellers and need to live much closer to the school they attend. This means it is much easier to infer which schools are accessible from a particular residential location. Moreover, admissions arrangements make it much easier for pupils in secondary schools to cross 
LEA boundaries - which would undermine the identification strategy we described above. At primary level, there are institutional barriers hindering admission of pupils to schools outside their home LEA and only a very small number do so. ${ }^{11}$ Aside from this, there are good theoretical reasons for focussing on primary-age attainments, because educational and behavioural development at primary age is critical for life-time success (Heckman (2000), and Dearden et al. (2004)).

Although primary school pupils tend to live quite close to their schools, there is still a great deal of scope for parents to choose between alternative schools in the state sector. All primary schools are non-selective, but there is variety in terms of the way schools are governed and admissions organised, and schools differ in terms of aims, ethos and religious character. The basic division is between institutions which are affiliated with a church and "Community" schools which are not. Roughly $60 \%$ of schools are Community schools, 26\% Church of England, 11\% Catholic and the remaining $3 \%$ affiliated to other churches or charitable organisations. In most cases (75\%), the LEA administers school admissions. The LEA also funds the schools, mostly through central government grant, and provides administrative and managerial support. Importantly for the empirical work we carry out here, the law states that parental choice must be the guiding principle in prioritising admissions (although local differences exist in the way applications are prioritised when schools are over-subscribed). Indeed there is clear evidence in our data that admissions are not tied to place of residence since neighbouring pupils attend many different schools and only $48 \%$ of pupils attend their nearest school.

\footnotetext{
${ }^{11} 4.7 \%$ overall for Community school pupils in our sample. $85 \%$ of residents living right on the LEA boundary attend a school in their home LEA
} 
Our empirical analysis of the primary school system requires micro data on pupil attainments, linked to information on pupil background and residential addresses. This is available through the Department of Education and Skills' (DfES) National Pupil Database (NPD) for 1996-2003, linked to the Pupil Level Annual Census (PLASC) for 2002 and 2003. These are administrative survey datasets that cover the entire school population, and record pupil scores in standard tests at age 7 and age 11 (and higher ages in secondary school). Our focus is on the tests at age 7 and 11, the start and end dates of what is called Key Stage 2 in the UK National Curriculum. To construct measures of school-mean value-added between age 7 and 11, we work with standard DfES “point scores" which provide a summary measure of pupil achievement based on levels of attainment in maths, and English tests. The school value-added point score is simply the difference between age-11 and age-7 point scores, averaged at school level. To measure within school attainment dispersion at age 7 we convert the point scores into percentiles (in the whole sample) and then calculate the within-school Gini coefficient on these percentiles. To measure dispersion at age 11, we use the Gini on the percentiles of the actual test scores in these subjects (which are not available at age 7).

Pupil and school addresses are geo-coded to British National Grid coordinates using Ordnance Survey "Codepoint" data, which provides grid references for postcode unit (usually street) centroids. Finally - for our instrumental variables strategy - we derive LEA boundaries from the County and District boundaries obtainable from the 'UK Borders' service for Geographical Information Systems data. The sample is then restricted to a geographical zone within a $50 \mathrm{~km}$ radius of central London, in order to focus on primarily urban school markets. 


\subsection{Results}

Table 1 summarises the most important variables in the data we analyse, namely competition, performance and segregation measures. ${ }^{12}$ All variables are defined at the school level of aggregation. A key question regards the amount of variation in the competition and segregation measures. If all schools serve only the local community, or if any school within an LEA is easily accessible from any residence within an LEA, then there is no variation in the level of competition. Similarly, if all schools are populated by similarly heterogeneous pupils, or if all neighbourhoods are characterized by diversified students, with schools implementing no differential admission policies, then our polarization measures would display no variation. Table 1, and Figures 3 and 4 below, show that that our data display some interesting features.

\section{TABLE 1 ABOUT HERE}

Looking first at the competition index, the first row of Table 1 tabulates summary statistics, while Figure 3 graphs the distribution of the competition index for all schools, and Figure 4 (taken from Gibbons el al. (2006)) maps of the spatial distribution of school competition in London (part of our study area); these all show there is substantial variation in the competition indices we have at hand. ${ }^{13}$ Around 1 in 4 pupils have no school (other than the one they attend) within a short travel distance, but only 1 in 10 schools have all pupils with no local alternatives. Finally, from the map in Figure 4 we

\footnotetext{
${ }^{12}$ Descriptive statistics for a set of controls used in our analysis are reported in Table A1.

${ }^{13}$ Additional details can be found in Gibbons et al. (2005).
} 
can also deduce that the competition indices are only partly related to urban centrality and density.

The central panel of Table 1 reports summary statistics for our measures of segregation. The Gini coefficient at the school level varies between 0.06 and 0.63 (with a standard deviation of 0.08 ): this suggests that the most segregated schools are ten times more homogeneous, in terms of their pupil ability, than the least polarized ones. The Gini index on the catchment areas we construct around schools shows a very similar pattern.

FIGURE 3 ABOUT HERE 
FIGURE 4 ON OWN LANDSCAPE PAGE ABOUT HERE 
Next, the panels of Figure 5 present a simple graphical analysis of the raw relationship between the competition a school faces and: a) its performance; and b) the mix of attainments of its pupils at age 7 . These plots are smoothed over the competition index range using running means, with $95 \%$ confidence intervals. Both the value-added measure and the dispersion in pupil attainments (Gini) show an increasing pattern: more competition is associated with higher-value-added and less stratified schools. Yet, as already mentioned, this result could simply be the result of unobserved neighbourhood factors, residential choice patterns and strategic school location.

\section{FIGURE 5 ABOUT HERE}

To go further, and estimate a causal impact of competition on either performance or stratification, we need to implement the strategy described in Section 2.4, that makes use of variation in competition near LEA boundaries. First, however, we start our analysis with simple ordinary least squares regression estimates, which model the relationships observed in Figure 5, with some additional control variables.

Columns 1 and 2 of Table 2 presents the first set of these regression results based on ordinary least squares (OLS) estimates of a regression of age-7 to age-11 pupil achievement progression (value added). Column 1 has no controls; Column 2, instead, includes a set of controls for school and neighbourhood characteristics (listed in Table A1). In both cases the coefficient on our competition index is strongly significant and the sign suggests that schools facing more competitive markets have a performance advantage. The order of magnitude is fairly small though, with a one standard deviation increase in our performance index - roughly one alternative school available to its 
pupils - associated with a $5 \%$ of a standard deviation increase in performance ${ }^{14}$. In Columns 3 and 4, we introduce our instrumental variables methodology, using the (logarithm of) distance to LEA boundaries as an instrument for school competition. ${ }^{15}$ The results of this are striking: with our without additional controls, our point estimates suggest that competition is really linked to marginally lower school performance, though the coefficients are not statistically significant. Yet, examination of the first stage coefficient and standard error, reported in the second row of Table 2, suggests that our instrument is quite powerful. Our interpretation is that exogenous changes in competition do not have a positive effect on school performance, and the OLS results simply pick up unobserved neighbourhood heterogeneity or the fact that pupils with a large number of alternative schools tend to choose the ones that perform best.

\section{TABLE 2 ABOUT HERE}

Even if competition has weak effects on mean attainments, there may be effects on pupil sorting which lead schools to become more stratified with some competitive schools attracting low-ability pupils and others attracting high-ability pupils. Or perhaps competition breaks the link between residential sorting and school stratification, leading to greater mixing of abilities in competitive schools. We investigate these issues in Table 3, which reports the results of regressions that model the within-school dispersion of age- 7 and age-11 attainments using the Gini index. All the figures in the first row are

\footnotetext{
14 These results are similar to those reported using pupil level regressions in Gibbons et al. (2005), though the school-level results here pick up the effects of both technological efficiency and sorting on school performance.

${ }^{15}$ While controlling for the average logarithm of the distance of schools to LEA boundaries in each LEA; this ensures that we are comparing like with like, taking into account the relative size and density of each LEA.
} 
multiplied by 100 , so they show the effect of a unit change in our competition index in percentage points.

Column 1-2 are simple OLS results without controls. Column 1 indicates that dispersion in attainment at age 7 is higher in schools that are located in what appear to be competitive markets; yet, this is not true for age 11 achievements where there the association is small in magnitude and statistically insignificant. Moving right across the table we first add some basic neighbourhood controls to account for neighbourhood heterogeneity. Now, the evidence for more dispersion of age-7 attainments in competitive schools is much weaker, and the age-11 attainments appear less dispersed in these schools. This suggests, perhaps, that unobserved neighbourhood attributes may be driving the first OLS results. Yet, one might argue that this method is inappropriate, because some of the effects of competition are absorbed by changes in neighbourhood composition. Turning to our IV methodology, however, gives us bigger negative point estimates (Columns 5-8), implying lower ability dispersion, or more school stratification, in competitive markets. The effect is similar whether we measure attainment at age- 7 or at age- 11 .

Although none of these IV coefficients is precisely estimated, they all suggest increased competition may have an economically meaningful impact on stratification by attainment. In fact, an increase of one in the number of alternatives with which a school has to compete ( 1 standard deviation in our index) reduces the Gini dispersion of attainments at age 7 by just under percentage point, i.e. $12.5 \%$ of a standard deviation. Then again, this means quite a substantial change if we move over the full range of the data: expanding the number of alternative schools from 0 to 8 would reduce withinschool dispersion Gini from 0.41 to 0.25 . 


\section{TABLE 3 ABOUT HERE}

Our results so far suggest there may be small adverse effects from competition on pupil performance, and somewhat larger impacts on school stratification. However, our estimates are imprecisely measured. One possibility is that competition has stronger impacts on neighbourhoods, even if the school stratification effects are quite weak. For example, an expansion of school choice, conditional on place of residence, may lessen residential sorting because it is no longer necessary to live close to a particular school in order to get in. We explore this hypothesis in Table 4, in an identical manner to Table 3 - but this time the Gini index is computed on the attainments of all pupils who live in the catchment area of a school, not just those who attend it. We define the catchment area using the area we construct for our competition measure. What we might expect to see is that neighbourhoods around schools that have many competitors are quite diverse, whilst those neighbourhoods which are served by just one school are more segregated. Looking across the Columns of Table, we see that this appears to be the case in the basic OLS estimates without controls (Columns (1) and (2)). But, again once controls are included in the age-7 models, or we use our LEA-boundary distance IV strategy, the coefficients become negative and insignificant. In fact, the pattern for the age-7 attainment mix in the neighbourhood is much the same as in the school models of Table 3 , though weaker. The pattern of results for age-11 attainments is more indicative of greater school competition (more parental choice) leading to reduced residential sorting; but again the estimates are imprecise. Interpretation of the age-11 results is also clouded by the fact that the mix of age-11 attainments in the neighbourhood will be depend on 
the effectiveness of the schools that serve the neighbourhood, and not just residential sorting.

\section{TABLE 4 ABOUT HERE}

Ultimately, the plausibility of our IV strategy depends on whether the first stages in the instrumented regressions are effective, and on whether the underlying assumptions are supported by the data.

Looking at the first stage coefficients reported in Tables 2 and 3, we see that a $10 \%$ increase in the distance from LEA boundary to a school increases the number of schools in the competition index by about 0.023 , or about $1.7 \%$ relative to the mean $(0.023 / 1.390)$. This instrument is significant, with t-statistics or around 10 . This is not an artefact of the fact that we impose the constraint the pupils do not cross LEA boundaries in the construction of our competition index. We can form the index without this restriction and get nearly identical results (see Table A2). In this case, identification comes from the fact that catchment areas shrink near LEA boundaries, because, according to our theoretical reasoning, pupils are more likely to attend their nearest schools given they have fewer schools within feasible travel distance.

Further results from pupil-level regressions show that the instrument works in line with this theoretical reasoning: the probability that a pupil attends their nearest school decreases with distance of their home from the nearest LEA boundary, and the average distance between a pupil's residence and the nearest 4 schools (other than the one he or she actually attends) decreases. In other words pupils near admissions district boundaries seem to be more constrained in their choice of school. 
Finally, we addressed the question of whether school or residence distance from LEA boundaries has a direct impact on pupil characteristics, and hence possibly on achievements and stratification. Yet again, we found this is not the case, lending further support to our IV strategy.

To conclude, our evidence using credible and powerful instrumental variables suggests that competition in primary schooling does not drive up school performance; if anything, policy that promotes competition through greater access in schooling markets may come at the cost of increased polarization in pupil achievements, and marginally worse performance.

\section{Concluding remarks}

Government education policies in England, as well as in the US and other countries, have increasingly expanded the role of parental choice, and competition among public schools, with the aim of improving educational outcomes. Critics of market-oriented reforms have however warned that these may come at the cost of increased stratification by pupil ability and attainments.

While a growing body of literature has been produced on the topic, evidence of the effects of competition on pupil achievements and segregation remains controversial, and a weak foundation for policy conclusions. In fact, most research has been confronted with the difficult challenge of finding credible exogenous variation to identify the effects of competition on pupil outcome.

In this chapter, we have presented a methodology to identify the impact of school competition and choice on pupil outcomes, using discontinuities in market access generated by proximity to administrative boundaries; this allows isolation of exogenous 
variation in the competitive pressure faced schools, which can be used to identify the impact of competition on pupil achievements and stratification by attainments.

Using a large pupil census with detailed information on pupil and school address, we have first constructed measures of school competition based on the number of alternative schools that pupils enrolled at a given institutions had, given their residence, the geographical location of schools, and the de-facto pupil travel-to-school patterns. This is an intuitive measure of competition, which can be easily extended to the analysis of other markets: competition pressures faced by a service provide are simply captured by the number of alternative that its users had within convenient travel distance. A drawback of these indices, shared with most of the alternatives used in previous analysis, is however that they may be endogenous to the quality of the service provided.

Our solution to this problem has exploited discontinuities in market access generated by clearly defined administrative boundaries. In fact, families near school admission district boundaries face a restricted choice compared to others in more central locations, because institutional barriers make it difficult for them to access schools on the other side of the boundaries, and it is costly to travel to alternatives further away towards the centre of the district. As a result, schools in the proximity of boundaries will enrol the vast majority of local students, and face little competition from other providers. We have argued that this methodology can be easily extended to similar contexts in the public service provision, such as public health, where access is ruled by zone of residence.

Our findings for English primary schools suggest that competition has no causal effect on the performance of schools. Most of the observed positive correlation between the number of competing schools and pupil attainments is driven by unobserved 
neighbourhood characteristics or endogenous selection of pupils with choice into better quality schools. Yet, we uncovered evidence that school competition may exacerbate stratification of schools by student attainment. Although our results are imprecisely estimated, they hint at a potentially large impact from expansion of competition on polarization of schools by pupil abilities. All in all, our analysis suggests that further expansion of quasi-market discipline in the public education sector may come at some costs, and with few evident benefits. 


\section{References}

Bayer, P. and McMillan, R., 2005. Choice and Competition in Local Education Markets. National Bureau of Economic Research Working Paper 11802.

Belfield, C., and Levin, H., 2003. The Effects of Competition between Schools on Educational Outcomes: A review for the United States. Review of Educational Research 72, 279-341.

Black, S., 1999. Do Better Schools Matter? Parental Evaluation of Elementary Education. Quarterly Journal of Economics 114, 578-599.

Bradley, S., and Taylor, J., 2002. The effect of the quasi-market on the efficiency-equity trade-off in the secondary school sector. Bulletin of Economic Research 54, 295-314.

Bradley, S., Crouchley, R., Millington, J. and Taylor, J., 2000. Testing for Quasi-Market Forces in Secondary Education, Oxford Bulletin of Economics and Statistics 62, 357-90.

Burgess, S., McConnell, B., Propper, C., Wilson, D., 2004. Sorting and Choice in English Secondary Schools. Centre for Market and Public Organisation W.P. 04/111, Bristol.

Clark, D., 2004. Politics, Markets and Schools: Quasi-Experimental Evidence on the Impact of Autonomy and Competition from a Truly Revolutionary UK Reform. Mimeo, University of California, Berkeley.

Cullen, J., Jacob, B., and Levitt, S., 2003. The Effect of School Choice On Student Outcomes: Evidence From Randomized Lotteries. National Bureau of Economic Research Working Paper 10113.

Cutler, D., and Glaeser, E., 1997. Are Ghettos Good or Bad?. Quarterly Journal of Economics 112, 827-872. 
Dearden, L., McGranahan, L., and Sianesi, B., 2004. The Role of Credit Constraints in Educational Choices: Evidence from NCDS and BCS70. Centre for the Economics of Education DP0048, London.

Gibbons, S., and Machin, S., 2003. Valuing English Primary Schools. Journal of Urban Economics 53, 197-219.

Gibbons, S., and Machin, S., 2006. Paying for Primary Schools: Supply Constraints, School Popularity or Congestion. Economic Journal, forthcoming.

Gibbons, S., Machin, S. and Silva, O., 2006. Competition, Choice and Pupil Achievement. Centre for Economics of Education DP0056, London.

Glennester, H., 1991. Quasi-Markets for Education. Economic Journal 101, 1268-76.

Goldstein, H. and Noden, P., 2003. Modelling social segregation. Oxford Review of Education 29, 225-237.

Gorard, S., Taylor, C. and Fitz, J., 2003. Schools, Markets and Choice Policies. Routledge-Farmer, London.

Hanson, G., 2003. What Has Happened To Wages In Mexico Since Nafta? Implications for Hemispheric Free Trade. National Bureau of Economic Research Working Paper 9563.

Hanushek, E., 2003. The Failure of Input-based School Policies. Economic Journal 113, F64-98.

Hanushek, E., Kain, J. and Rivkin, S., 2004. Disruption versus Tiebout improvement: the costs and benefits of switching schools. Journal of Public Economics 88, 1721-1746.

Heckman, J., 2000. Policies to Foster Human Capital. Research in Economics, 54, 3-56.

Hotelling, H., 1929. Stability in Competition, Economic Journal, 39, 41-57.

Hoxby, C., 1994. Do Private School Provide Competition for Public Schools? NBER Working Paper 4978. 
Hoxby, C., 2000. Does Competition Among Public Schools Benefit Students and Taxpayers?. American Economic Review 90, 1209-38.

Hoxby, C., 2003. School Choice and School Productivity (Or, Could School Choice be a Rising Tide that Lifts All Boats?), in: Hoxby, C. ed., The Economics of School Choice. University of Chicago Press, Chicago.

Hoxby, C., 2004. School Choice and School Competition: Evidence from the United States. Swedish Economic Policy Review, 10(2).

Hoxby, C., and Rockoff, J., 2004. The Impact of Charter Schools on Student Achievement, HIER Working Paper.

Kane, T, Steiger, D.O. and Reigg, S.K., 2005. School Quality, Neighborhoods and Housing Prices: The Impacts of Desegregation, National Bureau of Economic Research Working Paper 11347

Levacic, R., 2004. Competition and the Performance of English Secondary Schools: Further Evidence. Education Economics 12, 177-93.

Massey, D., and Denton, N., 1988. The Dimensions of Residential Sorting. Social Forces 67, 281-315.

Mobley, L., 2003. Estimating hospital market pricing: an equilibrium approach using spatial econometrics, Regional Science and Urban Economics 33, 489-516.

Propper, C., Burgess, S. and Green, K., 2004. Does competition between hospitals improve the quality of care? Hospital death rates and the NHS internal market. Journal of Public Economics 88, 1247- 1272.

Redding, S. and Sturm, D., 2005. The Costs of Remoteness: Evidence from German Division and Reunification, Centre for Economic Performance DP0688, London 
Rothstein, J., 2004. Good Principals or Good Peers? Parental Valuation of School Characteristics, Tiebout Equilibrium, and the Incentive Effects of Competition among Jurisdictions. National Bureau of Economic Research Working Paper Working Paper 10666.

Smith, B and Meier, K., 1995. Public Choice: Markets and the Demand for Quality Education. Political Research Quarterly 48, 461-478. 
Figure 1: Schematic presentation of the choice and competition measures

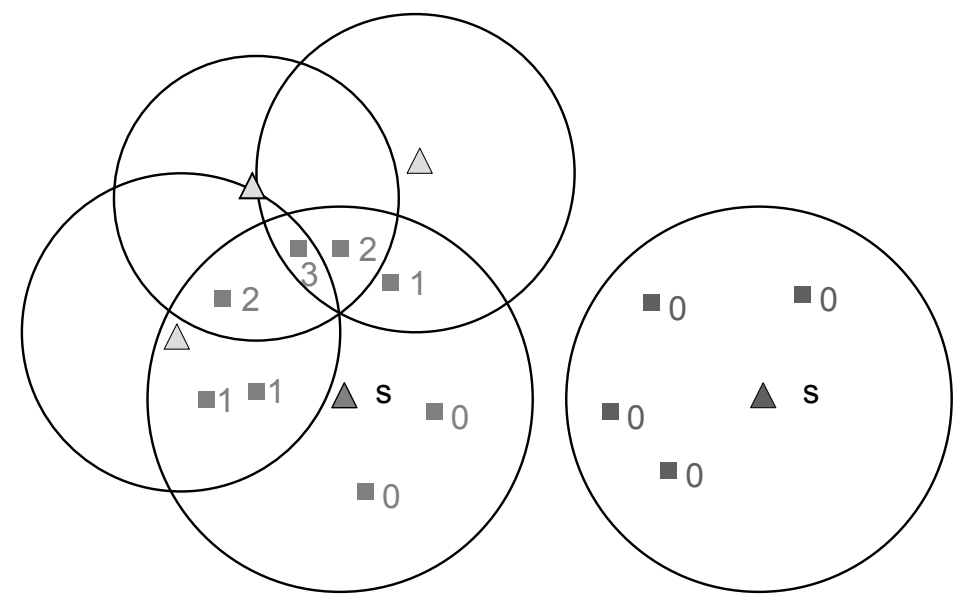

Competitive: $c_{s}=1.25 \quad$ Non-competitive: $c_{s}=0$

Number of schools accessible to pupils: Numbers $0,1,2,3$ indicate the choice index that would be assigned to pupils living in each area (assuming they attend school $s$ ) and the number $c_{s}$ is the average of these choice indices. 
Figure 2: Illustration of the instrumentation strategy

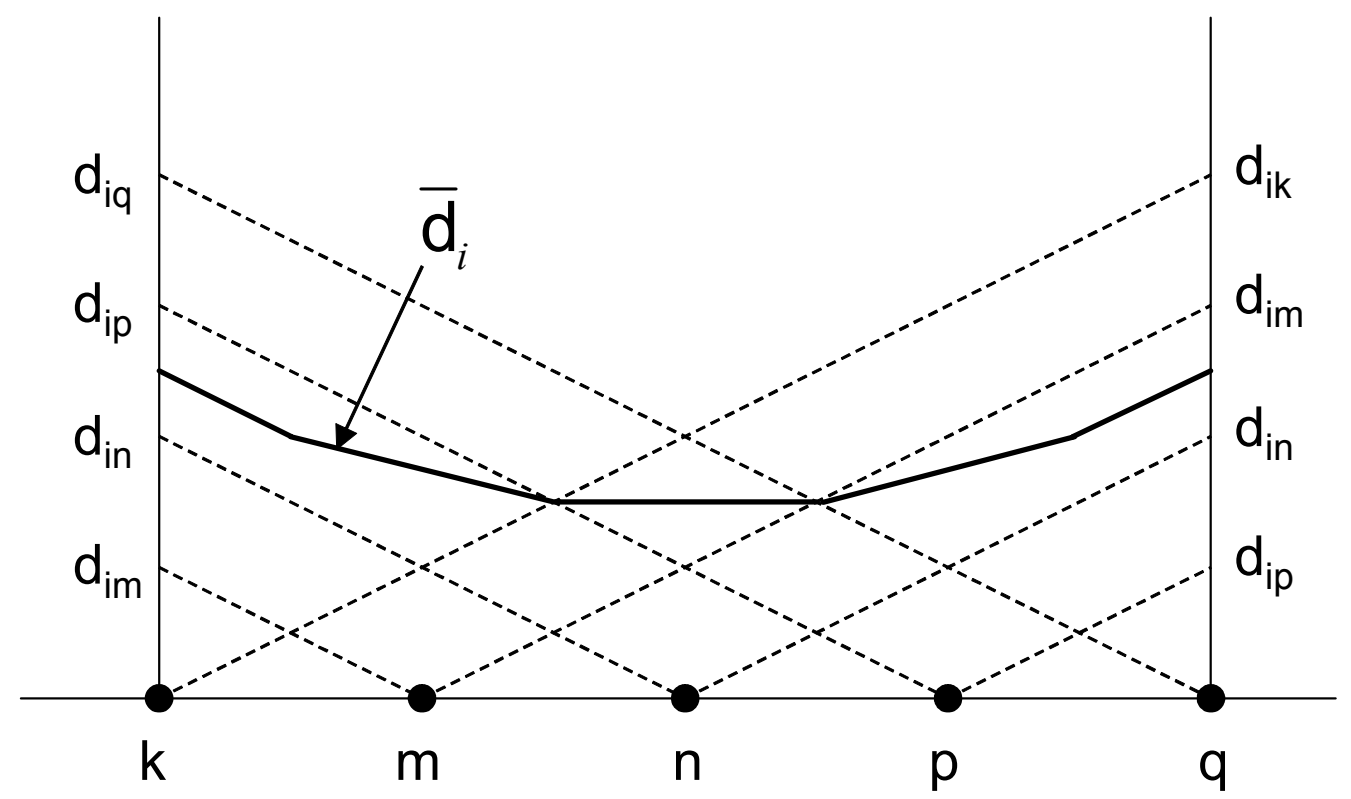

Figure shows a linear district with 5 schools, k,m,n,p,q; dij is the distance to each school; $\bar{d}_{i}$ is the average distance to schools other than the nearest. 
Figure 3: Distribution of the competition index

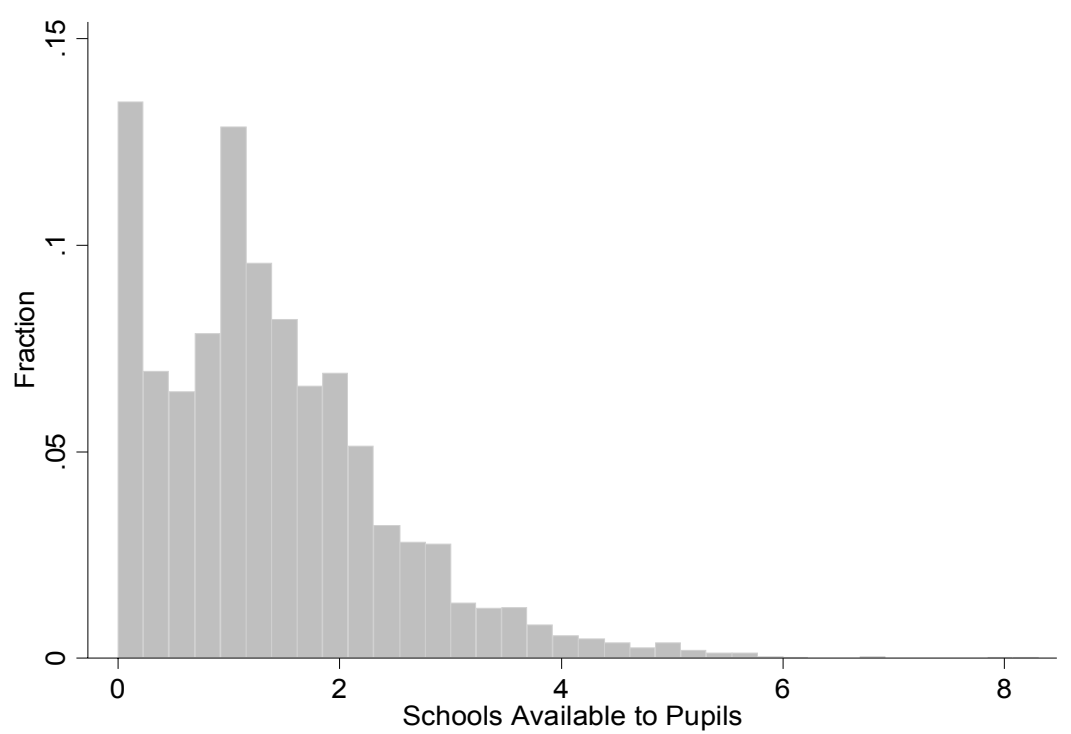


Figure 4: Primary School Competition in the Greater London Area

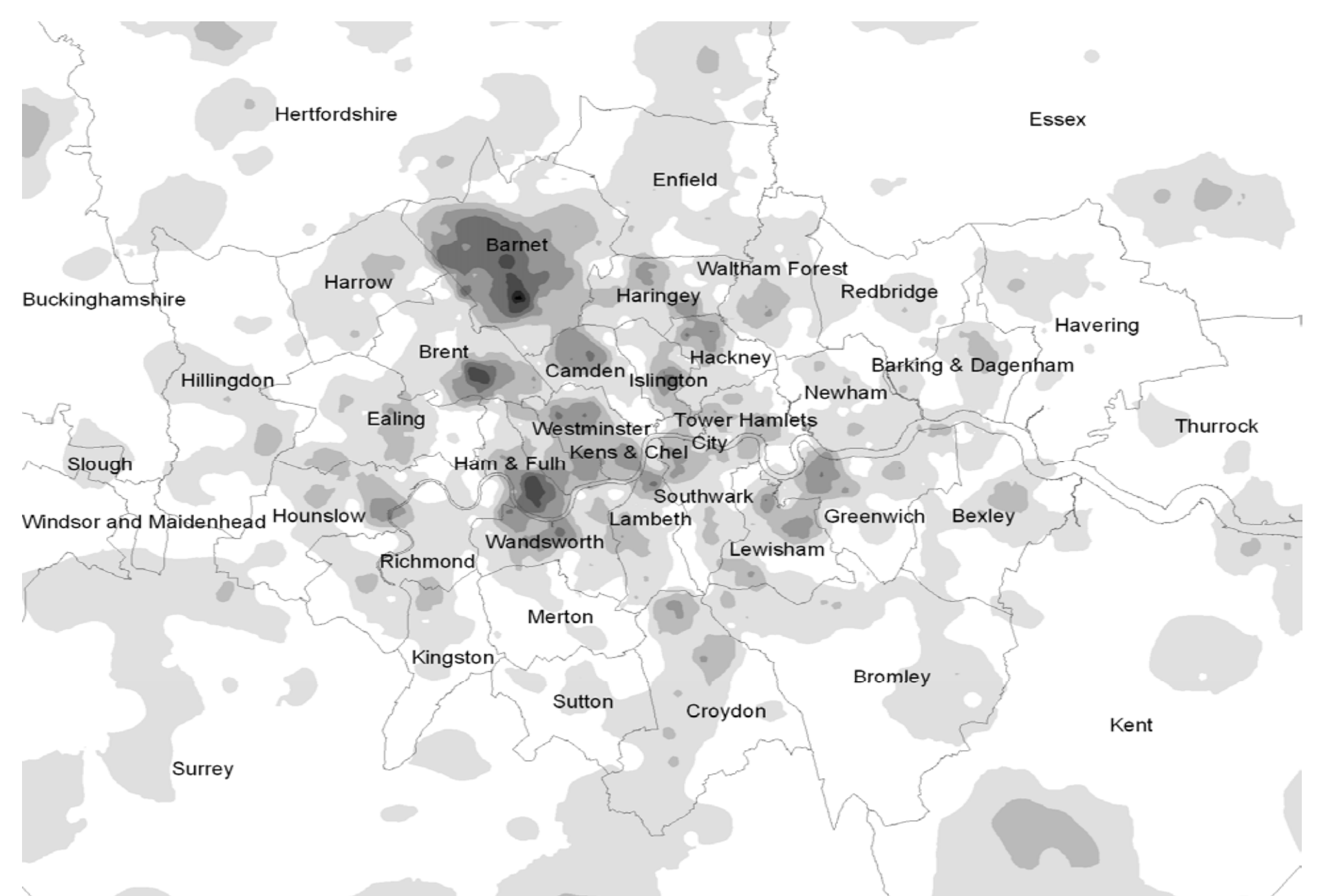

Figure shows local averages of the school-level competition index (Inverse Distance Weighted means of the nearest 6 schools on a 250m raster). Each shading class corresponds to intervals $[0,1],(1,2], \ldots(6,7]$ from lighter to darker. 
Figure 5a: Association between competition and school performance

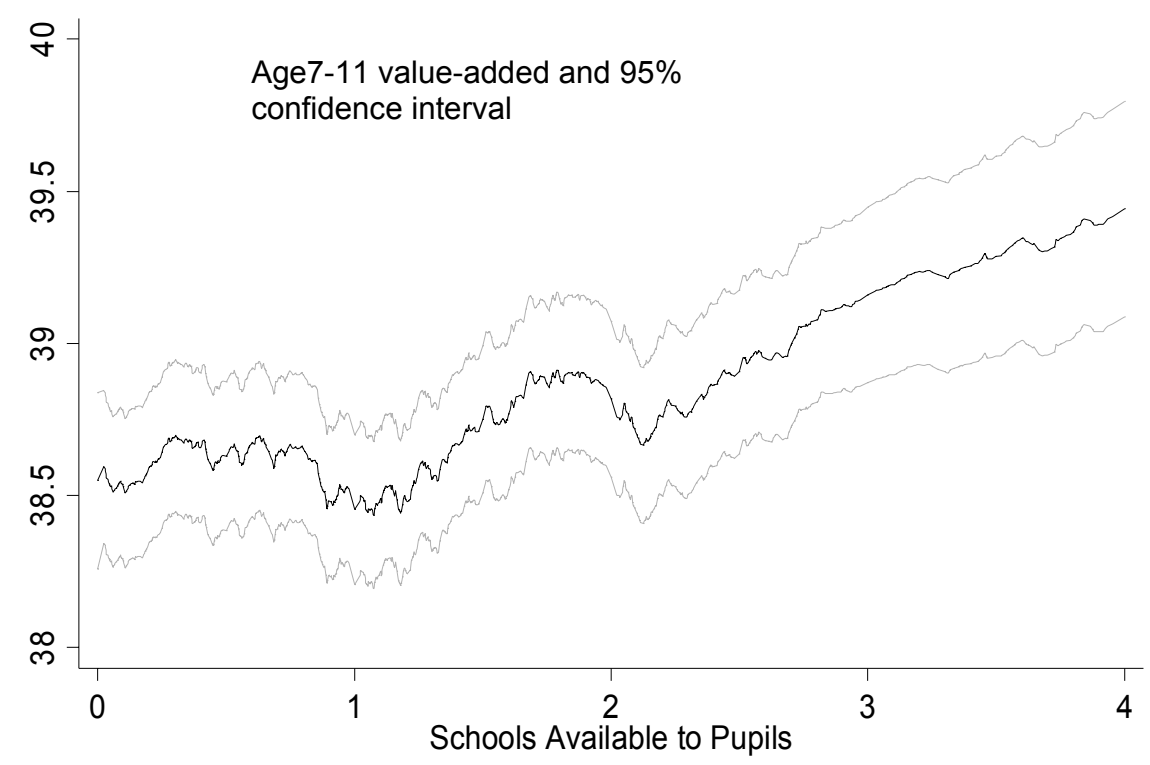

Figure 5b: Association between competition and within-school dispersion in attainment (Gini)

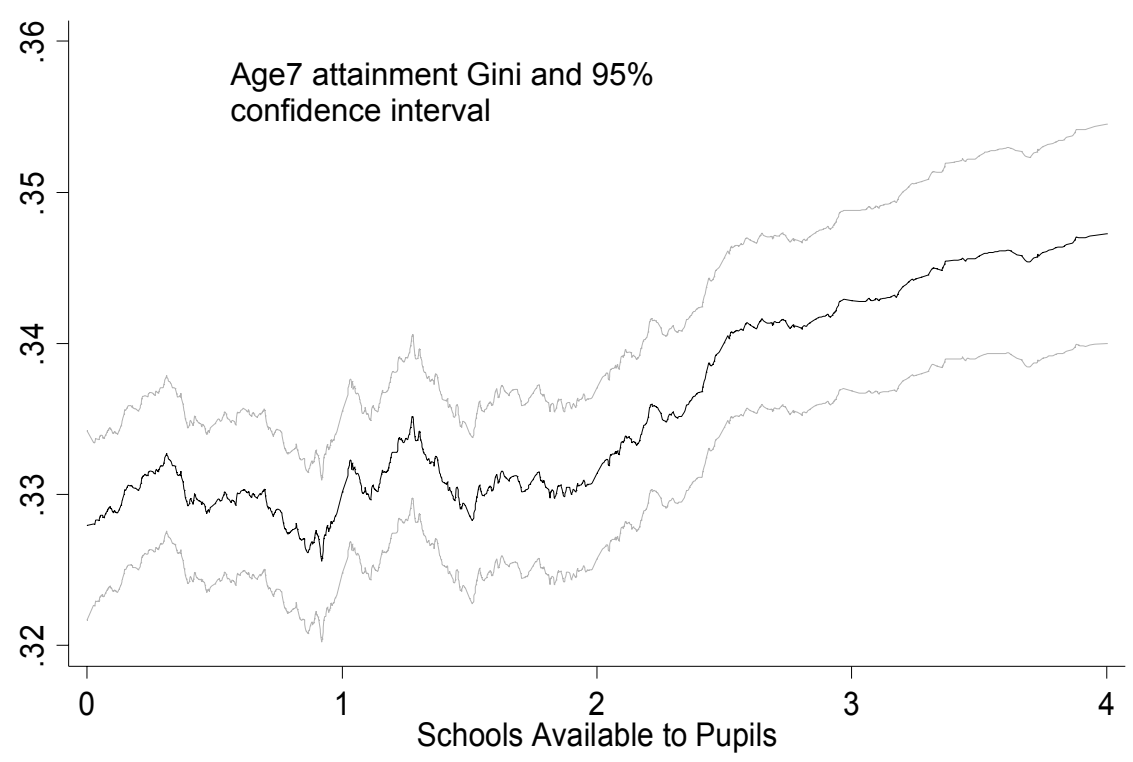


Table 1: Competition, stratification (Gini Coefficient) and value added; summary statistics

\begin{tabular}{lcccr}
\hline Variable & Obs. & Mean & Std. Dev. & Min, Max \\
\hline $\begin{array}{l}\text { Competition Measures } \\
\text { Average number of schools accessible to pupils in school }\end{array}$ & 4707 & 1.39 & 1.06 & $0,8.31$ \\
& & & & \\
Stratification Measures & & & & \\
Gini Coefficient, Pupils in School, Age-7 & 4707 & 0.33 & 0.08 & $0.06,0.63$ \\
Gini Coefficient, Pupils in School, Age-11 & 4703 & 0.31 & 0.08 & $0,0.60$ \\
Gini Coefficient, Catchment Area & 4707 & 0.34 & 0.08 & $0.06,0.58$ \\
& & & & \\
Performance Measures & 4707 & 38.72 & 3.70 & $23.16,55.18$ \\
KS2-1 Value Added & & & & \\
\end{tabular}


Table 2: Primary school competition and school performance 2001/2-2002/3

Age-7 to Age-11 value added points, pupils age 11 in 2001/2-2002/3

\begin{tabular}{|c|c|c|c|c|}
\hline & (1) & (2) & (3) & (4) \\
\hline & OLS & OLS & IV & IV \\
\hline $\begin{array}{l}\text { Competition index: number } \\
\text { of schools }\end{array}$ & $\frac{0.222}{(0.064)}$ & $\frac{0.197}{(0.073)}$ & $\begin{array}{l}-0.261 \\
(0.309)\end{array}$ & $\begin{array}{l}-0.294 \\
(0.316)\end{array}$ \\
\hline \multicolumn{5}{|l|}{ First Stage Regression } \\
\hline $\begin{array}{l}\text { Ln of school-LEA } \\
\text { boundary distance }\end{array}$ & -- & -- & $\frac{0.232}{(0.020)}$ & $\frac{0.224}{(0.018)}$ \\
\hline Controls & No & Yes & No & Yes \\
\hline
\end{tabular}

Regression at the school level. Standard errors clustered on school in parentheses: underline significant at $5 \%$; bold underline significant at 1\%. Controls are listed in Appendix A Instrument is the log of the distance between school and LEA boundary, controlling for the log average school-LEA boundary. Number of schools: 2412; number of observations 4707. 
Table 3: Primary school competition and school stratification

Gini index of within-school attainments, pupils age 11 in 2001/2-2002/3 scaled 0-100

OLS IV

Age-7 Age-11 Age-7 Age-11 Age-7 Age-11 Age-7 Age-11

$\begin{array}{lllllll}(1) & (2) & (3) & (4) & (5) & \text { (6) } & \end{array}$

$\begin{array}{lrlllllll}\text { Competition } & \underline{0.423} & -0.040 & 0.219 & -0.199 & -0.962 & -0.657 & -0.367 & -0.261 \\ \text { index: number } & (0.137) & (0.145) & (0.133) & (0.148) & (0.689) & (0.674) & (0.696) & (0.678)\end{array}$

of schools

First Stage

Regression

\begin{tabular}{lllllll}
$\begin{array}{l}\text { Ln school-LEA } \\
\text { boundary }\end{array}$ & -- & -- & $\underline{0.232}$ & $\underline{0.232}$ & $\underline{0.213}$ & $\underline{0.214}$ \\
\hline
\end{tabular}

Distance

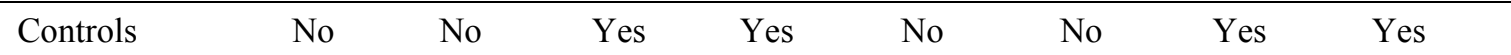

Regression at the school level. Standard errors in parentheses, clustered on school: underline significant at 5\%; bold underline significant at 1\%. Controls are listed in Appendix A, excluding: fraction of females, of FSM students and SEN students at school, and postcode level controls. Instrument is the log of the distance between school and LEA boundary, controlling for the log average school-LEA boundary. Number of schools: 2412; number of observations 4707 (4703 in age-11 models). 
Table 4: Primary School Competition and neighbourhood stratification, 2001/2-2002/3.

\begin{tabular}{|c|c|c|c|c|c|c|c|c|}
\hline & \multicolumn{8}{|c|}{ Stratification in Catchment Area } \\
\hline & \multicolumn{4}{|c|}{ OLS } & \multicolumn{4}{|c|}{ IV } \\
\hline & Age-7 & Age-11 & Age-7 & $\begin{array}{c}\text { Age- } \\
11\end{array}$ & Age-7 & Age-11 & Age-7 & Age-11 \\
\hline & (1) & (2) & (3) & (4) & (5) & (6) & (7) & (8) \\
\hline $\begin{array}{l}\text { Competition } \\
\text { index: number } \\
\text { of schools }\end{array}$ & $\frac{0.902}{(0.104)}$ & $\frac{0.416}{(0.103)}$ & $\begin{array}{c}0.193 \\
(0.104)\end{array}$ & $\begin{array}{r}-0.171 \\
(0.103)\end{array}$ & $\begin{array}{l}-0.060 \\
(0.511)\end{array}$ & $\begin{array}{c}0.552 \\
(0.510)\end{array}$ & $\begin{array}{l}-0.451 \\
(0.537)\end{array}$ & $\begin{array}{c}0.075 \\
(0.543)\end{array}$ \\
\hline $\begin{array}{l}\text { First Stage } \\
\text { Regression }\end{array}$ & & & & & & & & \\
\hline $\begin{array}{l}\text { Ln school- } \\
\text { LEA boundary } \\
\text { distance }\end{array}$ & -- & -- & -- & -- & $\frac{0.232}{(0.020)}$ & $\frac{0.232}{(0.020)}$ & $\frac{0.213}{(0.018)}$ & $\frac{0.213}{(0.018)}$ \\
\hline Controls & No & No & Yes & Yes & No & No & Yes & Yes \\
\hline
\end{tabular}

Regression at the school level. Standard errors in parentheses, clustered on school: underline significant at $5 \%$; bold underline significant at 1\%. Controls are listed in Appendix A. Instrument is the log of the distance between school and LEA boundary, controlling for the log average school-LEA boundary. Number of schools: 2412; number of observations 4707. 


\section{Appendix}

Appendix Table A1: Controls, summary statistics

\begin{tabular}{|c|c|c|c|c|}
\hline Variable & Observations & Mean & $\begin{array}{l}\text { Std. } \\
\text { Dev. }\end{array}$ & Min, Max \\
\hline \multicolumn{5}{|l|}{ School Level Variables } \\
\hline Fraction of Female in Schools & 4707 & 0.477 & 0.042 & 0,1 \\
\hline Pupil/Qualified Teacher Ratio & 4707 & 23.25 & 4.27 & $11.2,108.3$ \\
\hline Total School Size & 4707 & 324.3 & 132.02 & 52,1373 \\
\hline Fraction of Pupils with SEN & 4707 & 0.211 & 0.091 & $0,0.65$ \\
\hline Fraction of Pupils with FSME & 4707 & 0.210 & 0.167 & $0,0.77$ \\
\hline Median travel distance all schools & 4707 & 755.99 & 520.51 & 102,6157 \\
\hline Number of pupils in the travel area & 4707 & 75.59 & 74.93 & 2,1015 \\
\hline Average school distance from competitors & 4707 & 217.50 & 328.37 & 0,3525 \\
\hline \multicolumn{5}{|l|}{ Postcode Level Variables } \\
\hline Fraction of Lone Parents & 4707 & 0.282 & 0.127 & $0,0.617$ \\
\hline Fraction of Unemployed & 4707 & 0.040 & 0.020 & $0,0.104$ \\
\hline Fraction With no School Qualifications & 4707 & 0.267 & 0.075 & $0,0.576$ \\
\hline Fraction with Black Ethnicity & 4707 & 0.088 & 0.101 & $0,0.557$ \\
\hline Fraction with Chinese Ethnicity & 4707 & 0.019 & 0.015 & $0,0.128$ \\
\hline Fraction with Other Asian Ethnicities & 4707 & 0.090 & 0.120 & $0,0.766$ \\
\hline \multicolumn{5}{|l|}{ LEA Level Controls } \\
\hline Total LEA Expenditure in 2000 (in $£ 1000$ ) & 4707 & 2258.39 & 1747.31 & $493.5,5982.7$ \\
\hline LEA Area (in $1,000,000$ squared metres) & 4707 & 719.31 & 1100.18 & $12.4,3450.8$ \\
\hline
\end{tabular}


Appendix Table A2: Primary School Competition, school performance and school stratification, 2001/2-2002/3; without no-LEA boundary crossing restriction

Age-7 to Age-11 value added School stratification points

Age-7 (KS1)

\begin{tabular}{|c|c|c|c|c|}
\hline & (1) & (2) & (3) & (4) \\
\hline & OLS & IV & OLS & IV \\
\hline Competition index: number of schools & $\frac{0.205}{(0.069)}$ & $\begin{array}{l}-0.635 \\
(0.701)\end{array}$ & $\begin{array}{l}-0.150 \\
(0.121)\end{array}$ & $\begin{array}{l}-0.423 \\
(1.543)\end{array}$ \\
\hline
\end{tabular}

First Stage Regression

\begin{tabular}{|c|c|c|}
\hline $\begin{array}{l}\text { Logarithm of School-LEA boundary } \\
\text { Distance }\end{array}$ & -- & $\frac{0.103}{(0.019)}$ \\
\hline
\end{tabular}

\begin{tabular}{lcccc}
\hline Controls & Yes & Yes & Yes & Yes \\
\hline
\end{tabular}

Regression at the school level. Standard errors clustered on school: underline significant at 5\%; bold underline significant at $1 \%$; $t$ statistics in parentheses. Controls are listed in Appendix A; controls in columns 6, 8 and 10 do not include: fraction of females, of FSM students and SEN students at school, and postcode level controls. Instrument is the $\log$ of the distance between school and LEA boundary, controlling for the log average school-LEA boundary. Number of schools: 2412; number of observations 4707. 